Western University

Scholarship@Western

Bone and Joint Institute

$8-1-2020$

\title{
A Large-Scale Fifteen-Year Minimum Survivorship of a Cementless Triple Tapered Femoral Stem
}

\author{
Evangelos Tyrpenou \\ University of Toronto Faculty of Medicine \\ Amir Khoshbin \\ University of Toronto Faculty of Medicine \\ Shoaib Mohammad \\ The University of Sydney \\ Emil H. Schemitsch \\ Western University \\ James P. Waddell \\ University of Toronto Faculty of Medicine
}

See next page for additional authors

Follow this and additional works at: https://ir.lib.uwo.ca/boneandjointpub

Part of the Medicine and Health Sciences Commons

\section{Citation of this paper:}

Tyrpenou, Evangelos; Khoshbin, Amir; Mohammad, Shoaib; Schemitsch, Emil H.; Waddell, James P.; and Atrey, Amit, "A Large-Scale Fifteen-Year Minimum Survivorship of a Cementless Triple Tapered Femoral Stem" (2020). Bone and Joint Institute. 1054.

https://ir.lib.uwo.ca/boneandjointpub/1054 
Authors

Evangelos Tyrpenou, Amir Khoshbin, Shoaib Mohammad, Emil H. Schemitsch, James P. Waddell, and Amit Atrey

This article is available at Scholarship@Western: https://ir.lib.uwo.ca/boneandjointpub/1054 
Primary Hip

\title{
A Large-Scale Fifteen-Year Minimum Survivorship of a Cementless Triple Tapered Femoral Stem
}

\author{
Evangelos Tyrpenou, MD ${ }^{\text {a, }{ }^{*}, 1}$, Amir Khoshbin, MD, MSc, FRCSC a , \\ Shoaib Mohammad ${ }^{\mathrm{b}}$, Emil H. Schemitsch, MD, FRCSC ${ }^{\mathrm{c}}$, \\ James P. Waddell, MD, FRCSC ${ }^{\text {a }}$, Amit Atrey, MB BS , MSc, FRCS (Tr \& Orth) ${ }^{\text {a }}$ \\ a Division of Orthopaedics, University of Toronto, Saint Michael's Hospital, Toronto, Ontario, Canada \\ b School of Medicine, University of Sydney, Sydney, New South Wales, Australia \\ c Department of Surgery, University of Western Ontario, London Health Sciences Centre - University Hospital, London, Ontario, Canada
}

\section{A R T I C L E I N F O}

\section{Article history:}

Received 2 February 2020

Received in revised form

12 March 2020

Accepted 15 March 2020

Available online 21 March 2020

\section{Keywords:}

total hip arthroplasty

total hip replacement

cementless

long-term survivorship

synergy stem

\begin{abstract}
A B S T R A C T
Background: This study reports the long-term outcomes of a metaphyseal fit-and-fill cementless femoral component in total hip arthroplasty (THA) with a follow-up of 15-19 years.

Methods: We conducted a retrospective review of 376 consecutive THAs (345 patients), using a triple tapered stem performed between 2000 and 2003 with a view to assessing survivorship and radiological and functional outcomes. Images were assessed for initial alignment, terminal osteolysis, or subsidence, while clinical outcomes were assessed using the St Michael's Hip Score.

Results: Forty-five (11.9\%) hips were lost to follow-up, 20 (5.31\%) had died before our 15-year cutoff follow-up, and 4 (1.06\%) had declined follow-up early on, leaving 307 hips (81.64\%, 276 patients) available for both clinical and radiological follow-up at a minimum of 15 years (range 15-19). The mean age at the time of operation was 49.6 years (range 19-71) and the cohort included $131(42.67 \%)$ male and 145 (47.23\%) female patients. Seven stems (2.28\%) were revised: 4 due to periprosthetic fractures, 2 for periprosthetic joint infection, and 1 for adverse reaction to metal debris at the trunnion. The St Michael's Hip Score improved from 14.2 (range 9-23) preoperatively to 22.3 (range 13 to 25) at the last documented follow-up $(P=.000)$. Kaplan-Meier survivorship with stem revision for any reason as the end point was $97.70 \%$. Worst-case scenario Kaplan-Meier survivorship, where all lost to follow-up are considered as failures, was $85.3 \%$. No stem was revised for aseptic loosening.

Conclusion: This triple tapered stem in THA shows excellent survivorship beyond a minimum of 15 years.
\end{abstract} (C) 2020 Elsevier Inc. All rights reserved.
Evangelos Tyrpenou helped in data collection and analysis, and wrote the paper; Amir Khoshbin helped in data research; and Shoaib Mohammad helped in data research and statistical analysis.

Amir Khoshbin, Emil H. Schemitsch, James P. Waddell, and Amit Atrey are coeditors; Emil H. Schemitsch and James P. Waddell are primary surgeons; and Amit Atrey is a supervising author.

One or more of the authors of this paper have disclosed potential or pertinent conflicts of interest, which may include receipt of payment, either direct or indirect, institutional support, or association with an entity in the biomedical field which may be perceived to have potential conflict of interest with this work. For full disclosure statements refer to https://doi.org/10.1016/j.arth.2020.03.028.

Funding: This research did not receive any specific grant from funding agencies in the public, commercial, or not-for-profit sectors.

* Reprint requests: Evangelos Tyrpenou, MD, Division of Orthopaedics, University of Toronto, Saint Michael's Hospital, 55 Queen St E, Level 8, Toronto, Ontario M5B 1W8, Canada.

${ }^{1}$ Current address: 2-1561 Rue De Gascogne, Laval, Quebec H7N 6C7, Canada.
The debate between cemented and uncemented femoral stems in hip arthroplasty is ongoing. Although the cemented implant was the only option until the early 1980s and results into the 3rd decade are excellent, the use of uncemented femoral implants is almost ubiquitous in North America and rising in the rest of the world [1,2]. However despite its gain in popularity, published data of cementless hip arthroplasty survivorship beyond 15 years remain limited [3-16].

Analysis of the Joint Registry data in the UK and Australia has shown that revisions for aseptic loosening in cementless femoral stems are low, particularly in young patients under the age of 65 years [17].

The Synergy Cementless stem (Smith \& Nephew, Memphis, TN) was introduced in 1996. It is a proximally coated triple tapered implant (tapered in 3 planes; coronal, sagittal, and axial) and available in 4 circumferential finishes: porous, hydroxyapatite (HA) coated, porous and HA, and a grit blasted. It is made of high- 
strength forged titanium with a $3^{\circ}$ proximal to distal taper. Parallel and longitudinally arranged proximal anterior and posterior flutes provide additional stability.

The trunnion taper is $12 / 14$ with a small anteroposteriorly polished neck to minimize impingement and maximize stability. Neck angle remains at $131^{\circ}$ for both standard and high offset necks. Proximal pore size is 200 microns. Almost 100\% pure HA is sprayed with 50 microns over a grit-blasted surface. Coating distally is gritblasted to promote ongrowth and the bullet shaped tip is polished to prevent bone growth, aiming to reduce the chances of thigh pain. This stem achieves initial stability through 3-point fixation, at the posterior proximal neck, anteriorly midway through the metaphysis, and at the posterior cortex distally.

There are reports with excellent mid-term [18-22] and more recently long-term (15 years) survivorship [23,24]. The purpose of our study is to demonstrate the survivorship of this fit-and-fill cementless stem in a larger consecutive cohort of patients to add to the weight of evidence of implant survivorship with a minimum follow-up at 15 years (15-19).

\section{Method}

This is a retrospective review of the records of sequential patients that received a total hip arthroplasty (THA) using this metaphyseal fit-and fill, proximal to distal tapered stem design, from the year 2000 to 2003. Institutional Research Ethics Board approval was obtained before the initiation of the study (REB\# 18-014 ${ }^{\mathrm{C}}$ ).

All operations were performed at a single institution by 2 senior authors (J.P.W. and E.H.S, ) via the posterolateral approach. The stem chosen was surgeon's preference and therefore 2 types were used: the proximally porous coated by one surgeon (E.H.S.) and the proximally HA coated by the other (J.P.W.). The acetabular component was a mixture of 2 shells-Interfit Reflection and Reflection SNR (Smith \& Nephew) - and 3 liners including ultrahigh-molecular-weight polyethylene (UHMWPE), aluminaceramic, and more latterly highly cross-linked polyethylene (XLPE). All patients were allowed to weight bear as tolerated with the use of an assistive device, from postoperative day 1 , and they were restricted to no active abduction and flexion beyond $90^{\circ}$ of their operated side for 6 weeks.

The patients were evaluated preoperatively and at 3 weeks, 6 months, annually up to 10 years, and every 5 years after surgery or recalled as part of this final review. The validated patient-reported outcome measure, the St Michael's Hospital Hip Score [25,26], was documented at each visit and X-rays were taken consisting of an anterior-posterior supine pelvic and cross-table lateral view of the operated side. Radiological assessment was performed by a fellowship-trained orthopedic surgeon not involved in the operations (E.T.) and secondary evaluation and auditing was performed by an attending surgeon (A.A.). X-rays were assessed for stem implantation alignment (varus, valgus, or neutral as defined by Khalily and Lester [27]). The angle formed between the medial endosteal cortex of the femoral shaft and the shaft of the implant was used to determine the degree of varus angulation. When the angle was more than $5^{\circ}$ then the stem was characterized as varus or valgus respectively. The morphology of the femoral canal was defined by the Dorr Classification [28]. All patients (except 4) had a Dorr A or B classification. During this 3-year period, all other Dorr C patients were treated with a cemented or fully porous coated cementless stem.

Stem subsidence was defined as the inferior migration of the stem of more than $2 \mathrm{~mm}$ from the initial postoperative X-ray

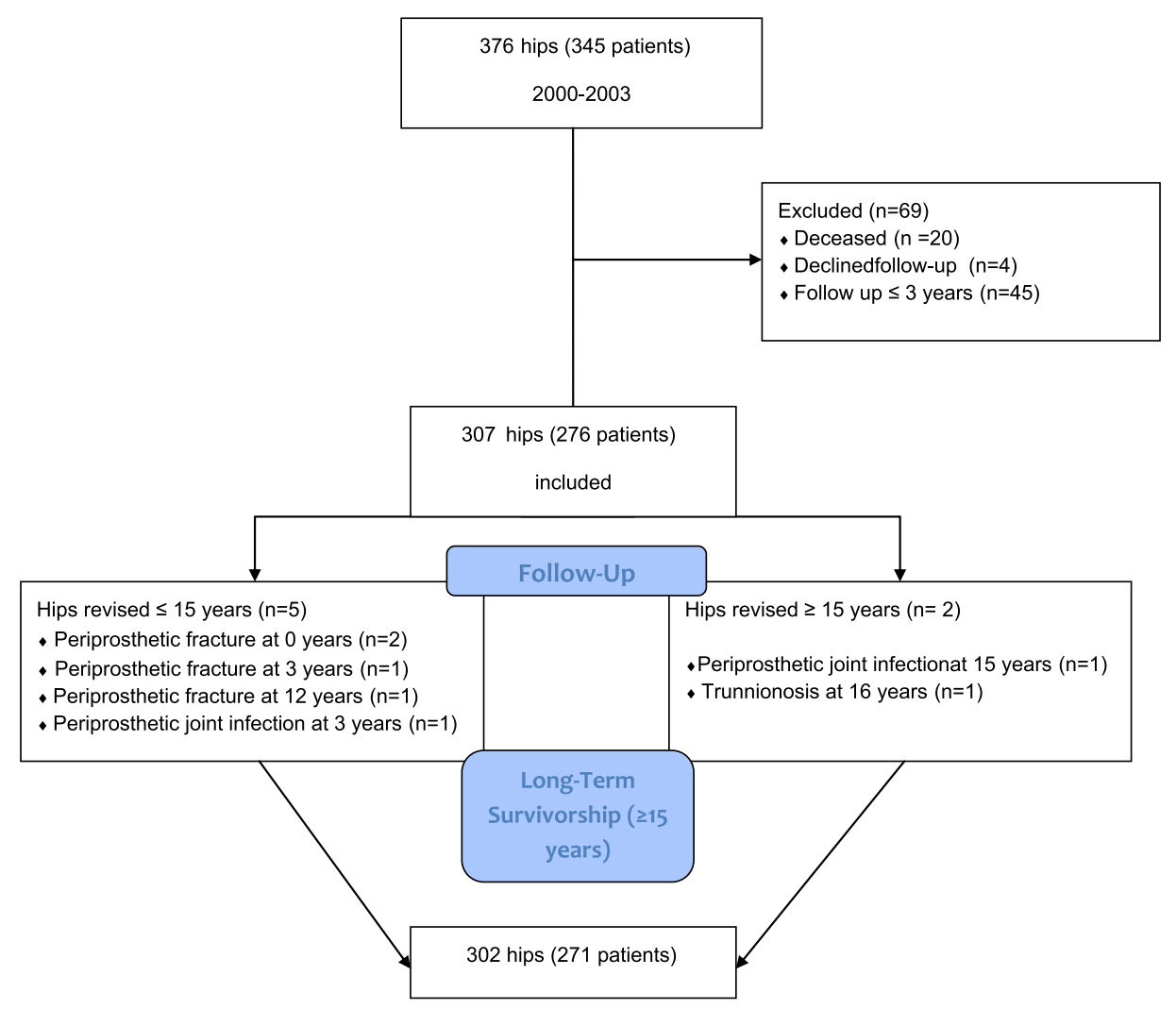

Fig. 1. The flow chart of our cohort. 
Table 1

The Demographic Characteristics of the Cohort.

\begin{tabular}{ll}
\hline Hips & 307 \\
Patients & 276 \\
Gender (male/female) & $131 / 145$ \\
Side (right/left) & $175 / 132$ \\
Mean age at surgery (range) & $49.6(19-71)$ \\
Door classification (A/B/C) & $250 / 53 / 4$ \\
Diagnosis preoperatively & \\
Osteoarthritis & 178 \\
Developmental hip dysplasia & 59 \\
Avascular necrosis & 45 \\
Rheumatoid disease & 13 \\
Trauma & 11 \\
Hip fusion & 1 \\
Femoral components & \\
Proximally porous coated Synergy & 149 \\
HA coated Synergy & 158 \\
Acetabular components & \\
Interfit Reflection cell & $138(45.0 \%)$ \\
Reflection SNR cell & $169(55.0 \%)$ \\
Liners & \\
Alumina-ceramic & $94(30.6 \%)$ \\
Standard (UHMW) polyethylene & $172(56.0 \%)$ \\
XLPE polyethylene & $41(13.3 \%)$ \\
Heads & \\
Alumina-ceramic & $103(33.5 \%)$ \\
Cobalt-chrome & $204(66.4 \%)$ \\
\hline
\end{tabular}

HA, hydroxyapatite; UHMW, ultra-high-molecular-weight; XLPE, highly crosslinked polyethylene.

[29]. It was scored by measuring the vertical distance from the shoulder of the femoral component to the tip of the greater trochanter on a calibrated X-ray. Finally, radiological and clinical complications involving femoral and acetabular components were noted as well.

\section{Statistical Analysis}

Descriptive statistics were created for all outcomes. Data were collected and analyzed on Microsoft Excel Software (Microsoft Corporation, Redmond, WA). Survivorship analysis was conducted by creating Kaplan-Meier survivorship curves. Statistical analysis was performed using IBM SPSS Statistics, version 16 (IBM, New York, NY). A Student's paired $t$-test was utilized to assess clinical outcome. $P$ value $<.05$ was considered statistically significant.

\section{Results}

Three hundred seventy-six consecutive THA cases (345 patients) were performed using this metaphyseal fit-and-fill femoral stem in Dorr A and B femurs. We identified all of those cases with documented clinical and radiological data at a minimum of 15 years (1519) of follow-up. In total, 69 hips (18.27\%, 69 patients) were lost to follow-up. Twenty (5.31\%) patients had died before our 15-year follow-up cutoff. Four (1.06\%) patients declined follow-up at 1, 4, 7 , and 7 years respectively, as they moved far from our institution, but denied any revision of their hip. For the remaining 45 hips, last follow-up was less than 3 years postoperatively and we were unable to locate them. The flow chart of our cohort can be seen in Figure 1.

In total, 307 (81.64\%) hips in 276 patients were available for clinical and radiological evaluation for a minimum 15-year followup. The mean age was $48.6 \pm 11$ (range 19-71) at the time of operation. On hundred forty-five (47.23\%) females and 131 (42.67\%) males comprised our cohort. One hundred forty-nine hips (48.53\%) received the proximally porous coated and 158 (51.46\%) the proximally HA coated one. Stem offset was determined by preoperative templating and intraoperative judgment by the treating surgeon. Therefore 188 hips (61.23\%) received a standard offset stem and 119

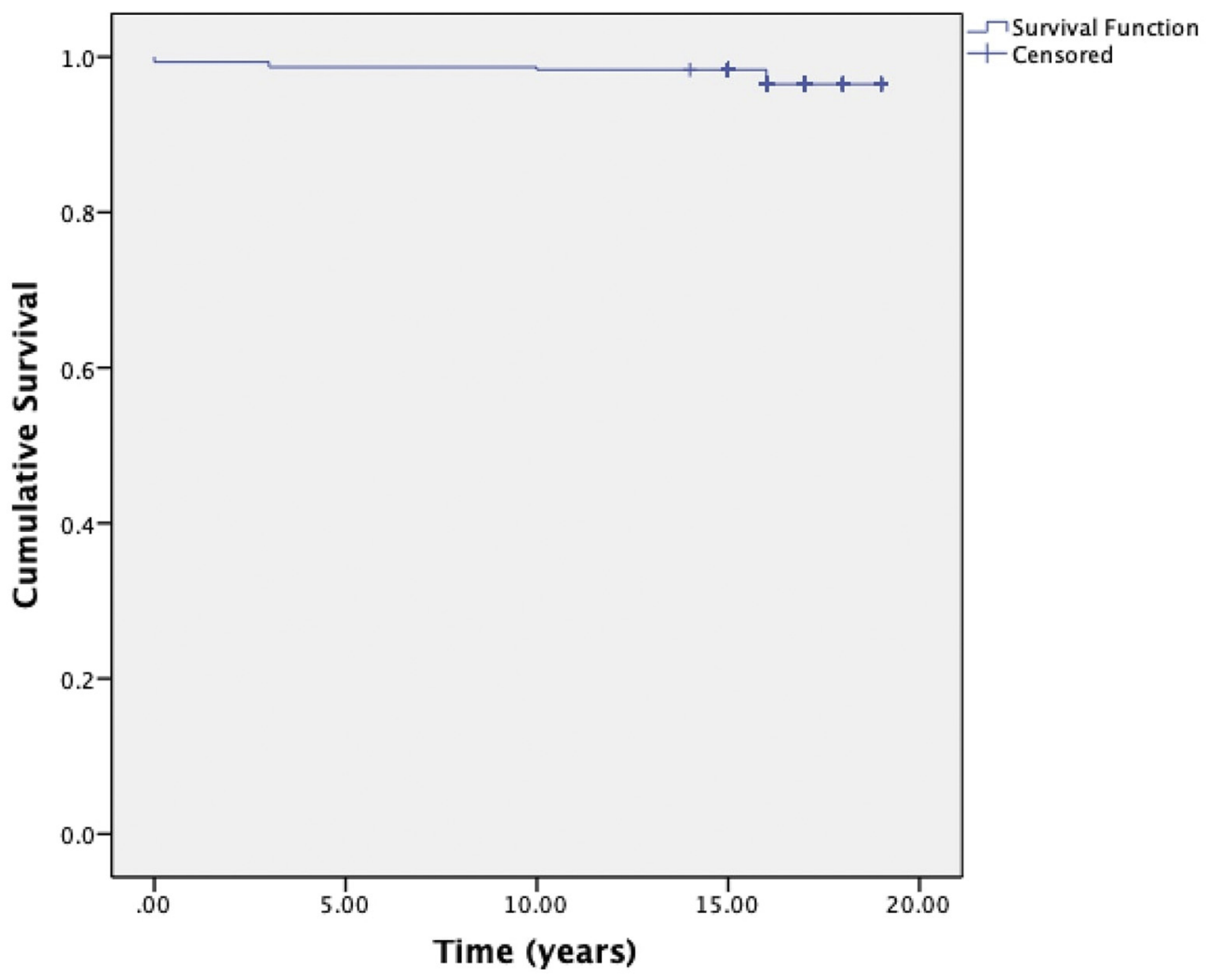

Fig. 2. Kaplan-Meier survivorship curve with stem revision for any reason as end point. 
hips (38.76\%) a high offset. To further analyze this, 107 of the 188 standard offset hips (56.91\%) were of male patients and 64 of the 119 high offset hips (53.78\%) were of female ones.

The 2 acetabular components used were 138 Interfit Reflection (45\%) and 169 Reflection SNR (55\%) (Smith \& Nephew). Acetabular liners used were 94 alumina-ceramic (30.6\%), 172 UHMWPE (56.0\%), and more latterly 41 XLPE (13.3\%). Femoral heads included 103 alumina-ceramic (33.5\%) and 204 metal head (66.4\%). The demographic characteristics of our cohort are shown in Table 1.

Seven stems (2.28\%) in 7 patients were revised. Four of these were due to periprosthetic fractures. Two patients were diagnosed with periprosthetic fractures in the immediate (within days) postoperative period, either when still hospitalized or recovering at a rehabilitation center. Two patients were revised at 3 years and 12 years for Vancouver B2 periprosthetic fractures after falls. Both stems were well fixed and asymptomatic prior to the incident but were revised to a modular device and cerclage wires.

Two more patients were revised for periprosthetic joint infection at 3 and 15 years respectively and underwent a 2-stage revision. Both stems were well bonded and an extended trochanteric osteotomy was required for extraction.

One patient was revised for fractured ceramic acetabular liner with an incidental finding of trunnionosis at 16 years. The revision took place initially for exchange of fractured ceramic liner but the finding of significant and surprising trunnionosis (Goldberg grade 3) [30] led to stem revision as well.

No stem showed any evidence of subsidence. Thirty stems (9.77\%) were implanted in varus but all survived our last follow-up of over 15 years, with no clinical evidence of pain documented.

Acetabular revisions occurred in 8 cases (2.6\%) for dislocation and 6 cases (1.95\%) for significant acetabular osteolysis in Gruen zones 1 and 2 (all associated with UHMWPE). Fourteen cases (4.56\%) were revised with either isolated head and liner exchange for UHMWPE wear or acute infection. One case $(0.32 \%)$ was revised by head and liner exchange for dislocation with a ceramic-on-ceramic bearing.

Mild proximal femoral osteolysis at Gruen zones 1 and 7 was observed in 31 cases (10.09\%) [31,32]. In all 31 cases, an UHMWPEmetal head coupling was used and there were no associated symptomatic findings, therefore regular observation was continued. None of the stems associated with an XLPE bearing have any associated osteolysis in any femoral or acetabular zone.

In 10 cases (3.25\%) of ceramic-on-ceramic coupling, squeaking had been reported by the patients, at various intervals in follow-up; however, none of these cases have been revised to date.

The St Michael's Hip Score improved from a mean of 14.2 (range 923) preoperatively to a mean of 22.3 (range 13-25) at final follow-up $(P=.000)$.

Kaplan-Meier survivorship with stem revision for any reason as the end point was $97.70 \%$ (Fig. 2), with a mean survival of 18.683 years (95\% confidence interval 18.438-18.928). The worst-case scenario survivorship where all cases lost to follow-up were considered as failures was $85.30 \%$ (Fig. 3), with a mean survival of 16.440 years (95\% confidence interval 15.781-17.098).

\section{Discussion}

The demand for THA is increasing rapidly along with an aging population. THA cases are predicted to be doubled by 2030 in the United States [33]. As a consequence, the revision rates and the associated social and economic burden will increase as well. One way to overcome those complications is the use of implants with proven excellent track record [33].

There are several studies showing good results in the short-term and medium-term follow-up for this stem [18-22]. However, long-

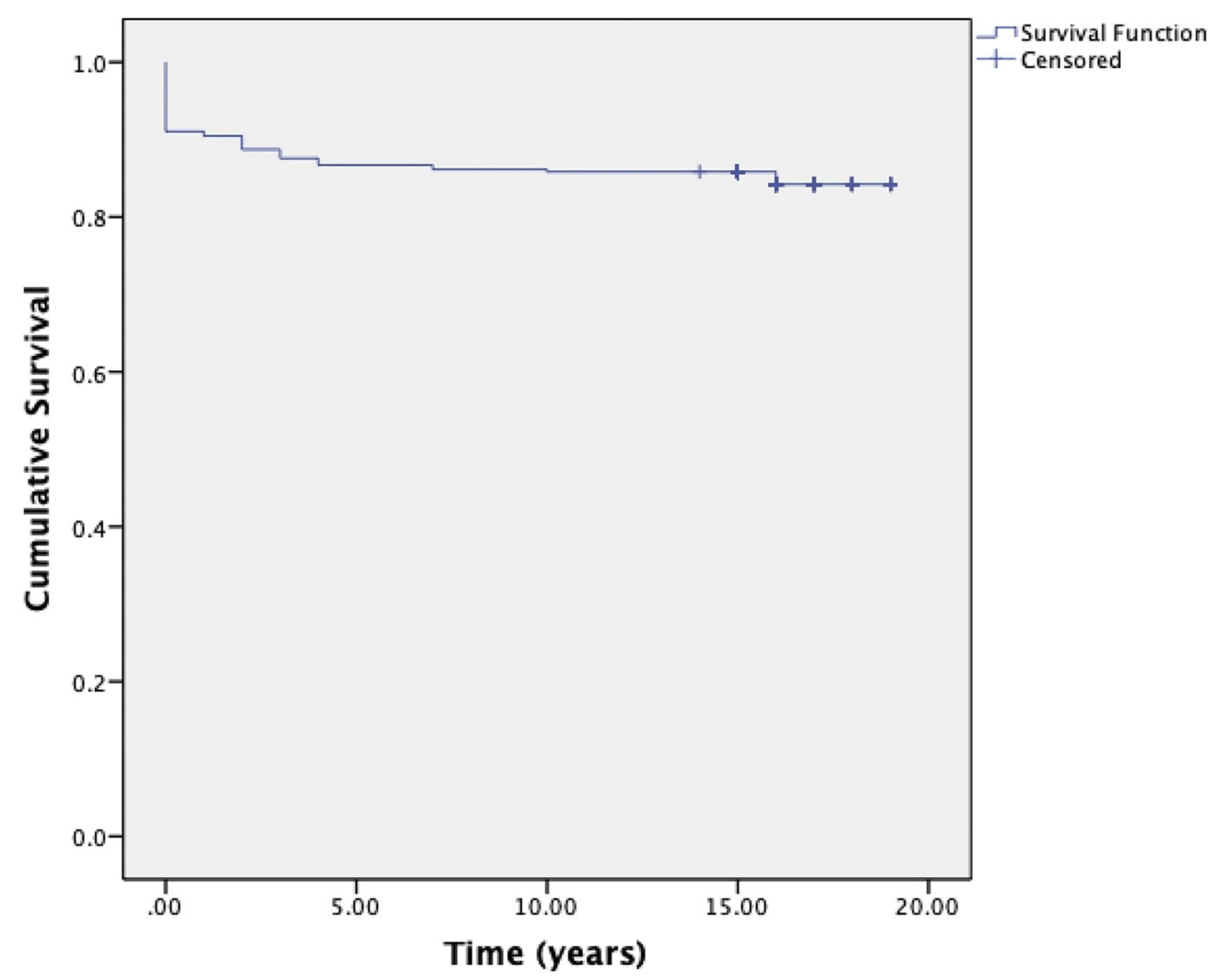

Fig. 3. Kaplan-Meier survivorship curve with worst-case scenario, where all those patients lost to follow-up were considered as failures. 
term follow-up (minimum of 15 years) is limited [23,24]. In the first study with a smaller cohort of 85 patients (94 hips), 4 stems were revised: 1 for aseptic loosening 7 months postoperatively, 1 for a Vancouver B2 periprosthetic fracture, and 2 for periprosthetic joint infections. Survivorship with stem revision for aseptic loosening as end point was 98.9\% at 15 years and for any cause was 95.7\% [23]. In a more recent study published in this journal, with a larger cohort of 210 patients, a total of 4 stems were revised: 1 for subsidence 3 months postoperatively, 2 for periprosthetic B2 fractures, and 1 for infection. Survivorship with stem revision for aseptic loosening as end point was $99.5 \%$ at 16 years and for any cause was $86.7 \%$ [24]. Our results are similar, with $97.70 \%$ survivorship for revision for any cause and no stems were revised for aseptic loosening.

Analyzing the data from the Australian Orthopaedic Association National Joint Replacement Registry, the cumulative percent for total hip revision for any reason in all THAs (with osteoarthritis and developmental dysplasia of the hip as primary diagnosis) at 16 years is 8.8 and 10.8, respectively [2]. More specifically, the revision rates for the Synergy Reflection coupling at 16 years are 5.8\% (5.1\% for the stem and $6.5 \%$ for the cup) [34].

Our study adds to the weight of evidence of excellent clinical and radiological survivorship at the medium to long-term for cementless femoral implants and further informs the debate over the cemented femoral implants (especially in the young population) $[3-17,35,36]$.

De Martino et al [23], in their radiographic analysis, reported stress shielding in a number of cases; however, this did not correlate with their outcomes and was described as "silent." This is in keeping with a previous study with a shorter follow-up period [18]. Only one report found symptomatic stress shielding in the Japanese population and this involved short stature patients, in whom larger stems were implanted [37].

Although long-term close observation for the cases that demonstrated proximal osteolysis is needed, it should be noted that this phenomenon occurred only when UHMWPE was used. With the almost exclusive use of XLPE as a bearing surface, this may not be a concern in the future.

In our study, $9.77 \%$ of stems were implanted in varus with no reported thigh pain and none has been revised to date. Our results correlate with a mid-term follow-up study (89 patients, 109 hips), which showed improved scores irrespective of whether the implant was inserted in perfect position or in varus. Pain and range of motion were not statistically significant between the 2 groups in that study [38]. Stress shielding was observed in all cases with varus alignment and the authors raised their concern about the effect on the survivorship of the implant in the long term [38]. In their follow-up of 210 stems, Panichkul et al reported that thigh pain had increased in incidence (from $2.8 \%$ to $3.8 \%$ ) at 16 years from their initial 8-year follow-up. But similarly, none of these required any intervention or affected patients' quality of life [24].

As it has been previously stated [24], the fit-and-fill design and the 3-point fixation that characterize this femoral implant allow for good early fixation and we assert for long-term survivorship.

Our study has several limitations. It is a retrospective report with no control group for comparison. There was heterogeneity with mixed acetabular and bearing components. Their inclusion in the survivorship may affect the overall revision rates. In those cases where the acetabular components were revised, however, none of the stems were removed.

Forty-five patients (13\%) were lost to follow-up, but this correlates with other studies looking into long-term survivorship of implants. Furthermore, the majority of our patients treated with this implant had femoral morphology type Door A and B. Type C femurs were treated by different implants as per surgeon's preference, which constitutes a degree of selection bias.
Finally, radiologic assessment was performed by 2 orthopedic surgeons; therefore, reliability of the results may be challenged. However, Engh et al [39] conclude that evaluation of periprosthetic bone loss on plane radiographs is questionable, since the loss is not reproducibly recognized until $70 \%$ of the bone is gone.

Although 2 recent studies [23,24] published similar results for their cohort using this fit-and-fill femoral stem, we report the largest sequential series of implants over 15 years to date, with no revisions for aseptic loosening of this femoral component.

In conclusion, this fit-and-fill femoral stem, with 3-point fixation, shows excellent long-term survivorship of $100 \%$ with revision for aseptic loosening as end point and $97.70 \%$ with revision for any reason. The survivorship is irrespective of the stem's offset and whether the coating was proximally HA or porous.

\section{References}

[1] No authors listed. The National Joint Registry, 16th annual report, September, 2019.

[2] Troelsen A, Malchau E, Sillesen N, Malchau H. A review of current fixation use and registry outcomes in total hip arthroplasty: the uncemented paradox. Clin Orthop Relat Res 2013;471:2052-9.

[3] Belmont Jr PJ, Powers CC, Beykirch SE, Hopper Jr RH, Engh Jr CA, Engh CA. Results of the anatomic medullary locking total hip arthroplasty at a minimum of twenty years: a concise follow-up of previous reports. J Bone Joint Surg Am 2008;90:1524-30.

[4] Corten K, Bourne RB, Charron KD, Au K, Rorabeck CH. What works best, a cemented or cementless primary total hip arthroplasty? Minimum 17-year follow up of a randomized controlled trial. Clin Orthop Relat Res 2011;469: 209-17.

[5] Lombardi Jr AV, Berend KR, Mallory TH, Skeels MD, Adams JB. Survivorship of 2000 tapered titanium porous plasma-sprayed femoral components. Clin Orthop Relat Res 2009;467:146-54.

[6] McLaughlin JR, Lee KR. Uncemented total hip arthroplasty with a tapered femoral component: a 22- to 26-year follow-up study. Orthopedics 2010;33: 639.

[7] Streit MR, Innmann MM, Merle C, Bruckner T, Aldinger PR, Gotterbarm T. Long-term (20- to 25-year) results of an uncemented tapered titanium femoral component and factor affecting survivorship. Clin Orthop Relat Res 2013;471:3262-9.

[8] Vidalain JP. Twenty-year results of the cementless Corail stem. Int Orthop 2011;35:189-94.

[9] Meding JB, Ritter MA, Keating EM, Berend ME. Twenty-year follow-up of an uncemented stem in primary THA. Clin Orthop Relat Res 2015;473:543-8.

[10] Sandiford N, Doctor C, Rajaratnam SS, Ahmed S, East DJ, Miles K, et al. Primary total hip replacement with a Furlong fully hydroxyapatite-coated titanium alloy femoral component: results at a minimum follow-up of 20 years. Bone Joint J 2013;95-B:467-71.

[11] Evola FR, Evola G, Graceffa A, Sessa A, Pavone V, Costarella L, et al. Performance of the CLS Spotorno uncemented stem in the third decade after implantation. Bone Joint J 2014;96-B:455-61.

[12] Müller LA, Wenger N, Schramm M, Hohmann D, Forst R, Carl HD. Seventeenyear survival of the cementless CLS Spotorno stem. Arch Orthop Trauma Surg 2010;130:269-75.

[13] Capello WN, D’Antonio JA, Jaffe WL, Geesink RG, Manley MT, Feinberg JR Hydroxyapatite-coated femoral components: 15-year minimum follow up. Clin Orthop Relat Res 2006;453:75-80.

[14] Suckel A, Geiger F, Kinzl L, Wulker N, Garbrecht M. Long-term results for the uncemented Zweymuller/Alloclassic hip endoprosthesis. A 15-year minimum follow up of 320 hip operations. J Arthroplasty 2009;24:846-53.

[15] Schwerter K, Meyenberg A, Sander K, Layher F, Roth A. [15-year results following implantation of a stem type AML hip prosthesis]. Z Orthop Unfall $2013 ; 151: 231-8$.

[16] Valkering LJ, Biemond JE, van Hellemondt GG. A wedge shaped uncemented femoral component: survivorship in patients under 50 years of age at a mean follow-up of 22 years. J Arthroplasty 2018;33:3226-30.

[17] Wyatt M, Hooper G, Frampton C, Rothwell A. Survival outcomes of cemented compared to uncemented stems in primary total hip replacement. World J Orthop 2014;5:591-6.

[18] Petis SM, Howard JL, McAuley JP, Somerville L, McCalden RW, MacDonald SJ Comparing the long-term results of two uncemented femoral stems for total hip arthroplasty. J Arthroplasty 2015;30:781-5.

[19] MacDonald SJ, Rosenzweig S, Guerin JS, McCalden RW, Bohm ER, Bourne RB, et al. Proximally versus fully porous coated femoral stems: a multicenter randomized trial. Clin Orthop Relat Res 2010;468:424-32.

[20] Naudie DD, Somerville L, Korczak A, Yuan X, McCalden RW, Holdsworth D, et al. A randomized trial comparing acetabular component fixation of two porous ingrowth surfaces using RSA. J Arthroplasty 2013;28:48-52.

[21] Nikolaou VS, Edwards MR, Bogoch E, Schemitsch EH, Waddell JP. A prospective randomized controlled trial comparing three alternative 
bearing surfaces in primary total hip replacement. J Bone Joint Surg $\mathrm{Br}$ 2012;94-B:459-65.

[22] Nishino T, Mishima H, Kawamura H, Shimizu Y, Miyakawa S, Ochiai N. Followup results of 10-12 years after total hip arthroplasty using cementless tapered stem-frequency of severe stress shielding with synergy stem in Japanese patients. J Arthroplasty 2013;28:1736-40.

[23] De Martino I, De Santis V, D'Apolito R, Sculco PK, Cross MB, Gasparini G. The Synergy cementless femoral stem in primary total hip arthroplasty at a minimum follow-up of 15 years. Bone Joint J 2017:99-B:29-36.

[24] Panichkul P, McCalden RW, MacDonald SJ, Somerville LE, Naudie DN. Minimum 15-year results of a dual-offset uncemented femoral stem in total hip arthroplasty. J Arthroplasty 2019;34:2992-8.

[25] Alpert B, Waddell JP, Morton J, Bear RA. Cementless total hip arthroplasty in renal transplant patients. Clin Orthop Relat Res 1992:164-9.

[26] McMahon JS, Waddell JP, Morton J. Effect of short-course indomethacin on heterotopic bone formation after uncemented total hip arthroplasty. J Arthroplasty 1991;6:259-64.

[27] Khalily C, Lester DK. Results of a tapered cementless femoral stem implanted in varus. J Arthroplasty 2002:17:463-6.

[28] Dorr LD, Faugere M-C, Mackel AM, Gruen TA, Bognar B, Malluche HH. Structural and cellular assessment of bone quality of proximal femur. Bone $1993 ; 14: 231-42$.

[29] Engh CA, Bobyn JD, Glassman AH. Porous-coated hip replacement. The factors governing bone ingrowth, stress shielding, and clinical results. J Bone Joint Surg Br 1987;69-B:45-55.

[30] Goldberg JR, Gilbert JL, Jacobs JJ, Bauer TW, Paprosky W, Leurgans S A multicenter retrieval study of the taper interfaces of modular hip prostheses. Clin Orthop Relat Res 2002:149-61.
[31] Goetz DD, Smith EJ, Harris WH. The prevalence of femoral osteolysis associated with components inserted with or without cement in total hip replacements. A retrospective matched-pair series. J Bone Joint Surg Am 1994;76-A:1121-9.

[32] Engh CA, Massin P, Suthers KE. Roentgenographic assessment of the biologic fixation of porous-surfaced femoral components. Clin Orthop Relat Res 1990;257:107-28.

[33] Kurtz S, Ong K, Lau E, Mowat F, Halpern M. Projections of primary and revision hip and knee arthroplasty in the United States from 2005 to 2030. J Bone Joint Surg Am 2007;89-A:780-5.

[34] No authors listed. Australian Orthopaedic Association National Joint Replacement Registry (AOANJRR). Annual report 2019.

[35] Purbach B, Kay PR, Siney PD, Fleming PA, Wroblewski BM. The C-stem in clinical practice: fifteen-year follow-up of a triple tapered polished cemented stem. J Arthroplasty 2013;28:1367-71.

[36] Burston BJ, Barnett AJ, Amirfeyz R, Yates PJ, Bannister GC. Clinical and radiological results of the collarless polished tapered stem at 15 years followup. J Bone Joint Surg Br 2012;94-B:889-94.

[37] Nishino T, Mishima H, Kawamura H, Shimizu Y, Miyakawa S, Ochiai N. Followup results of 10-12 years after total hip arthroplasty using cementless tapered stem frequency of severe stress shielding with synergy stem in Japanese patients. J Arthroplasty 2013;28:1736-40.

[38] Kawaji H, Uematsu T, Oba R, Hoshikawa N, Watanabe H, Takai S. Influence of femoral implant alignment in uncemented total hip replacemen arthroplasty: varus insertion and stress shielding. J Nippon Med Sch 2016;83:223-7.

[39] Engh Jr CA, McAuley JP, Sychterz CJ, Sacco ME, Engh Sr CA. The accuracy and reproducibility of radiographic assessment of stress-shielding. A postmortem analysis. J Bone Joint Surg Am 2000;82-A:1414-20. 